\title{
Conceptual Domains of KAU Revisited with Comments on Some Chinese KAU Researches*
}

\author{
Hui Chen ${ }^{1}$, Guojin Hou ${ }^{2}$ \\ ${ }^{1}$ Graduate School, Sichuan International Studies University, Chong Qing, China \\ ${ }^{2}$ College of Foreign Languages, Huaqiao University, Quan Zhou, China \\ Email: nationelf@126.com
}

Received 3 January 2016; accepted 19 February 2016; published 22 February 2016

Copyright (C) 2016 by authors and Scientific Research Publishing Inc.

This work is licensed under the Creative Commons Attribution International License (CC BY). http://creativecommons.org/licenses/by/4.0/

(c) (i) Open Access

\begin{abstract}
Firstly we briefly review the three conceptual domains of Sweetser (1990/2002), "content domain", "epistemic domain", and "speech-act domain" (Sweetserian trichotomy), and Shen (2003), the corresponding A(cting), K(nowing), U(ttering) (Shenian trichotomy)-our KAU, finding that they and their followers ignored largely the necessity to distinguish between these three domains in terms of the speaker, the listener and the other. Then, we clarify this issue and on this basis, analyze disadvantages of the study of three conceptual domains at the lexical level, thinking that previous studies failed to highlight the importance of syntactic and pragmatic factors to lexical level and thus did not rise to the pragma-syntactic level. On account of this, we put forward the "Lexico-Pragma-Syntactic Hypothesis" on the three conceptual domains, holding that the three of them should be studied by encompassing the three linguistic levels with pragmatics playing a prevailing role.
\end{abstract}

\section{Keywords}

Semantic Domains, Lexical Level, Speech Act, Contextual Cues, “Lexico-Pragma-Syntactic Hypothesis"

\section{Introduction}

Sweetser (1990/2002) discussed three different semantic functions of modal verbs like must, can, may etc., upon

\footnotetext{
"Here KAU is short (our shortening) for the three conceptual domains: “acting”, "knowing”, and "uttering” forwarded by Shen (2003)—respectively corresponding to Sweetser's (1990/2002) content, epistemic and speech-act domain.
} 
which he distinguished between three conceptual domains of human cognitive system, namely content domain, epistemic domain and speech-act domain and thereupon further explored how these three domains were realized in conjunctions as well as conditionals. By “content domain” Sweetser meant "the content of the sentence”, by "epistemic domain” he meant "the epistemic entity represented by the sentence" and by "speech-act domain” he meant "the speech act represented by the sentence" (Sweetser, 1990/2002: p. 72, 73). In other words, in this Sweetserian trichotomy, the content domain corresponded to "real world", the epistemic domain to "reasoning" and the speech-act domain to "speech act” (ibid.: p. 31). For example (ibid.: pp. 61, 73):

1) John may go.

2) John may be there.

3) May I ask you where you are going?

According to Sweetser, in such sentences as 1), the speaker expressed "real-world obligation, permission, or ability”, which implied that John was permitted to go. Thus, may belonged to the content domain (ibid.: p. 49). In 2), the speaker inferred the "necessity, probability, or possibility" of the event and thus thereby inferred that John was likely to be there. Here may denoted episteme, hence the epistemic domain (ibid.). In 3), however, the speaker did not really mean to ask for permission, but to require the listener to inform him as to where she would go. Thus, the illocutionary force of 3) was directive and so, according to Sweetser, may here expressed the meaning of the speech-act domain (ibid.: p. 73).

On ground of this formulation, Shen (2003) put forward three corresponding (derivative or synonymous) conceptual domains: "acting”, "knowing”, and "uttering” (KAU here for short)—respectively corresponding to Sweetser's content, epistemic and speech-act domain. According to Shen's statement, "acting” (A) referred to "the act and state in the real world, relevant to the state of actions and events", "knowing” (K) was "subjective consciousness and cognition, associated to the speaker's or listener's state of knowledge” and “uttering” (U) meant "a speech act for a purpose, such as a directive, a promise, a request etc., related to the state of speaking” (also see Xiao \& Shen, 2009; Austin, 1962/2002; Searle, 1969/2001). Take a look at the following examples (from Shen, 2003):

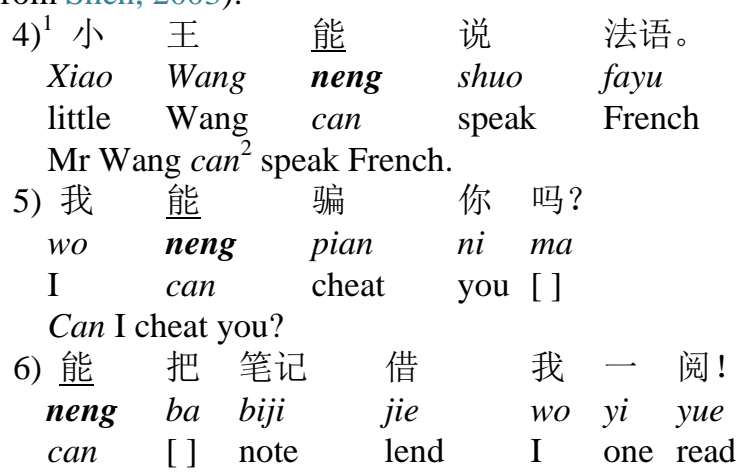

Can you lend me your notes?

It was Shen's belief that, among other things, neng in 4) denoted ability, which "directly related to act”, so here neng belonged to A. In 5), by using neng, the speaker did not ask himself/anyone whether he had the ability to cheat the listener, but instead asked the listener about the possibility of his cheating (her). Thus, this implied “an inference according to the known information" and neng here expressed the state of K. In terms of 6), the speaker did not ask whether the listener was able to lend him her notes or made an inference about the possibility of her lending her notes to him, but requested the listener to lend him her notes. Therefore, the speaker's words turned out to be an act and neng here was a token of $\mathrm{U}$.

In the framework of Shen and Sweetser, as we understand it, A (content domain) corresponds to the state of the real world, K (epistemic domain) denotes the speaker's inference, and U actually is the speaker's act through/by his utterance. In this way, their A is not (meant) for the speaker himself or the hearer but anyone else that is relevant - which is hereafter "(the) other", whilst the terms K and U are (meant) for the speaker proper. Here, "the other" (the target third person/entity mentioned in an utterance) is deemed to have to do with the

${ }^{1}$ Below there will be more Chinese examples like this in which the first one is the Chinese version of characters, the second one, the pinyin version, the third one, a literality version and the last one, a semantico-grammatical version.

${ }^{2}$ We italicize equivalent words wherever we think it is possible, knowing, though, that in the other/target language their function may be quite a different thing. And in cases of the italicized pinyin counterpart we boldface it. In case we find no counterpart, we leave "[ ]” where it is felt to be. 
speaker (the source of utterance) or it is no other than the listener (the receiver of utterance) herself. For instance, John and Mr Wang in the above examples are unmarked "others" because they are human beings. We can also find marked "others". In the sentence "My computer doesn't work.", my computer is "the other", but marked since it is an (inanimate) entity/object. Sometimes we will surely find that the target mentioned in an utterance is actually the speaker or the listener. For example, "I/You could play basketball”. Here the addresser or addressee (as the case varies) is the "other".

As far as we see it, if we want to distinguish between these three conceptual domains, we should firstly consider whose K, A, and U the so-called K, A, and U really are. A, in Sweetser's and Shen's model, is not A on the part of the speaker while $\mathrm{K}$ and $\mathrm{U}$ are the speaker's $\mathrm{K}$ and $\mathrm{U}$, so both of them seem to confuse the speaker, the listener and the other. Actually, any sentence is the content of speech and thus belongs to $\mathrm{U}^{3}$, presupposing a dose of $\mathrm{K}$ and implying a proportion of $\mathrm{A}$. Take the following sentence as an example.

7) He can swim with his arms bound like Prometheus.

Does this belong to U, K or A? According to Sweetser's and Shen's theorizing, it is A, describing the objective state of part of the real world. However, we see it as a unity of all the three. For one thing, 7) in its entirety is the content of the speaker's speech, and thus belongs to U. Furthermore, the speaker states this fact, presupposing that he knows it (K). Also, 7) describes the act of "him" (the other), and therefore denotes A.

Now that every sentence is the unity of the three things, how can we distinguish one from the other (s)? In our opinion, the key to this triadic differentiation lies in that we should bring into consideration perspectives or perspectivization: the speaker, the listener or the other. Actually, we should make it clear about which one is held prominent (see Langacker, 1987, 1991)/ostensive (see Sperber \& Wilson, 1986/1995/2001) in a sentence with respect to the perspective of the speaker, the listener or the other. If we put 7) in different contexts, it will naturally highlight $\mathrm{A}, \mathrm{K}$ or $\mathrm{U}$, but not two or three. What matters or tells is really the (right) perspective.

8) (“ ” is equivalent to 7))

a. $\mathrm{S}_{1}$ : I'm sorry, what did you say?

$\mathrm{S}_{2}: \sim$

b. $\mathrm{S}_{1}$ : What do you know about him?

$\mathrm{S}_{2}: \sim$

c. $\mathrm{S}_{1}$ : He can swim, can't he?

$\mathrm{S}_{2}: \sim$

As regards 8a), according to $S_{1}$ 's question, the most relevant understanding of $S_{2}$ is $U . S_{1}$ raises this question to inquire about the content of $S_{2}$ 's speech, so $S_{2}$ 's speaker/reporter identity is prominent/ostensive. Thus, this sentence should be understood from the speaker's perspective as the content of the speaker's speech (U). In 8b), $\mathrm{S}_{1}$ asks $\mathrm{S}_{2}$ about "him" (the other, a third party), actually posing a question with respect to $\mathrm{S}_{2}$ 's knowledge. Thus here it is $S_{2}$ 's $K$ that is prominent/ostensive. For 8c), $S_{1}$ asks $S_{2}$ whether "he" (the other, a third person) can swim. Here $S_{1}$ aims this question at "his" act. From a relevant perspective, $S_{2}$ 's answer should also be directed at the same act. In this context, "his" A is prominent/ostensive and this sentence should be seen from perspective of the other ("he" in this case), contributing (more) to A.

The question “Which domain does 7) belong to?” can be illustrated by Figures 1-4:

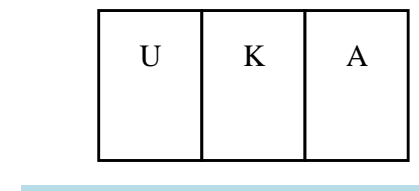

Figure 1. In default case.

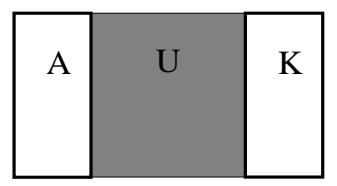

Figure 2. U is prominent/ostensive.

\footnotetext{
${ }^{3}$ Our "uttering” (U) refers to the content of speech, the conventional meaning of "uttering”, different from theirs (speech act). So does our "acting", denoting act, different from their objective state.
} 


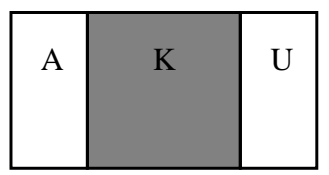

Figure 3. $\mathrm{K}$ is prominent/ostensive.

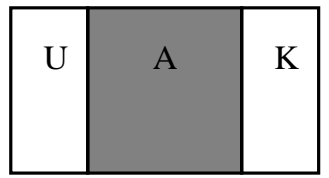

Figure 4. A is prominent/ostensive.

In default case, namely without any contextual information, 7) is (the speaker's) $\mathrm{U}$, (the speaker's) $\mathrm{K}$ and (the other's) A at the same time. However, in the context of 8a), (the speaker's) U is prominent/ostensive, and $\mathrm{K}$ and A become the background. In $8 \mathrm{~b}$ ), the prominent/ostensive one is (the speaker's) $\mathrm{K}$, and the background is $\mathrm{U}$ and A. With respect to 8c), (the other's) A is prominent/ostensive while $\mathrm{K}$ and $\mathrm{U}$ make background.

Therefore, in order to distinguish between these three domains, we deem it necessary to figure out $\mathrm{A}, \mathrm{K}$, and $\mathrm{U}$ in terms of the person in question, be it actor, knower, or utterer/locutor/sayer and in terms of prominence/ostension (i.e. which one is prominent/ostensive in a specific context).

Most studies about these three conceptual domains in China adopted Shen's (2003) definitions/trichotomy without asking any wh-questions. Hence, they invariably could be accused of the shortcoming of confusing the speaker, the listener and the other, as Sweetser (1990/2002) and Shen (2003) previously had done.

Generally speaking, these studies in China were carried out mostly at the lexical level. Researchers employed their trichotomy/theory to generalize various meanings, making use of Chinese adverbs, conjunctions, modal verbs, and so on. For instance, Li \& Liu (2004), Shi (2005), Xiao \& Shen (2009), Zhang (2011), Xiao (2011), Wang (2011), Xie (2014) and so on. There were also some scholars dealing with the issue at the syntactic level, like Shen (2003), Deng (2012), Wang (2012), etc. Others, like Xu (2008), Fan (2014) and so forth, explored the evolvement mechanism of the three domains.

The system of the three conceptual domains initially forwarded by Sweetser (1990/2002), and its Chinese version - the inheritance and development of Shen (2003) — provided a very practical framework for the explanation of many linguistic phenomena and helped to clarify the existing problems in previous studies. Therefore, their contribution to linguistic inquiries was doubtlessly valuable, as demonstrated by some studies in light of their model.

If, however, Sweetser and Shen formulated the three domains only by studies of a word in an utterance (like may, neng), or by studies of a clause (like (subordinate) conditional clause in a conditional (complex)), one word or clause definitely does not make any of the three above mentioned domains itself. A lexical item is supposed to be understood in a sentence (or co-text/context), so it seems that the study of the three domains should have begun with linguistic unities as large as, if not larger than, sentences. What's more, the studies in China confined themselves within the boundary of lexicon as listed above, which dwelt on a single word excessively, and this, as we think of it, by no means accounts for the multi-dimensional relation between the lexical, syntactic and pragmatic level. For this reason, we propose the "Lexico-Pragma-Syntactic Hypothesis" on the three conceptual domains, hoping to bridge up the gap left by previous studies.

\section{Disadvantages of the Study of Three Conceptual Domains at Lexical Level: From the Perspective of Chinese}

Firstly let's look at Xiao's (2011) study of ye (也; also) ${ }^{4}$ based on the theory of the above three conceptual domains. In his study, meanings of ye were generalized into " $Y E_{\mathrm{A}}$ ", " $Y E_{\mathrm{K}}$ ", and " $Y E_{\mathrm{U}}$ ". Then, " $Y E_{\mathrm{A}} \mathrm{P}$ " meant that "P was similar to some situation" and this "P usually referred to some act or state". In " $Y E_{K} \mathrm{P}$ ", "P was the particular knowledge on the part of the speaker, similar to the knowledge on the part of the others". As regards "YE $\mathrm{P}$ ", "P represented a speech act of the speaker, similar to the speech act of others". Please look at these

${ }^{4}$ Below there will be more sidenotes like this in which the first one is the Chinese character(s) for the preceding pinyin and the second is the literal meaning (see Note 2). 
examples, example 9) from Liu, Yi Di Ji Mao, qtd. from Xiao (2011), example 10) from Script of My Own Swordsman (qtd., ibid.), and example 11) from Chi, Yi Dong Wu Xue (qtd., ibid.).

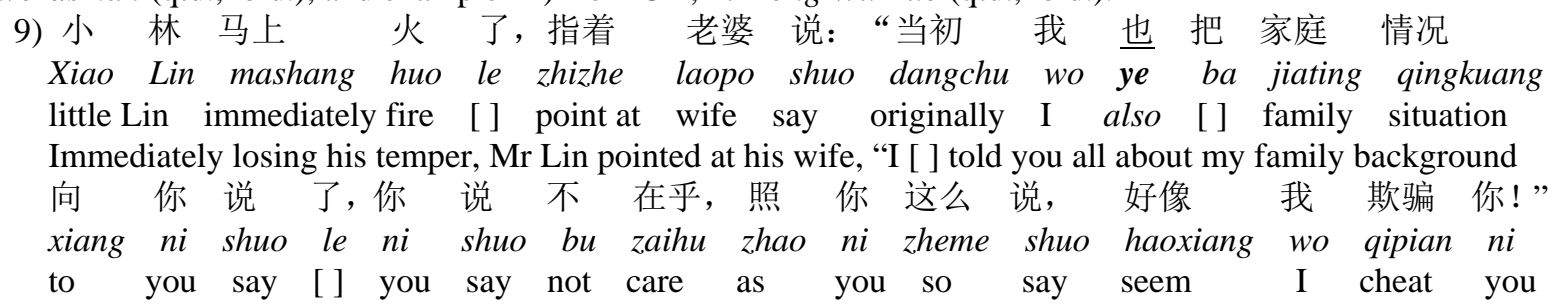
and you said you didn’t care a fig. But now you come to blame me for cheating!”

10) 你这又当嫂子年当娘的, 也真够辛苦的了。 ni zhe you dang saozi you dang niang de ye zhen gou xinku de le you this again as sister-in-law again as mother [ ] also real enough hard [ ] [ ] It is [ ] certainly hard of you, to be now both sister-in-law and mother of a kid.

11) “我 父母 对 你 说了我回去 的条件。我听我父母的。” “我再 wo fumu dui ni shuo le wo huiqu de tiaojian wo ting wo fumu de wo zai I parents to you say [ ] I go back [ ] condition I listen to I parents [ ] I again "As my parents told you what to do in order to get me back, I will do accordingly." "Let me tell you again 重申 一遍, 这是 我们的私事。” “可我也是你父母的儿媳妇。” chongshen yibian zhe shi women de sishi ke wo ye shi ni fumude erxifu restate once again this is we [] privacy but I also am you parents [] daughter-in-law that this is our absolute privacy!” "But I am also your parents’ daughter-in-law, aren’t I?”

With respect to 9), according to Xiao (2011), there existed such an affair: "If one intends to marry somebody, he should make his family background clear". The word ye in Mr Lin's utterance symbolized the situation similar to this objective affair and thus belonged to "YE $E_{\mathrm{A}}$ ". In 10), "ye zhen gou xinku de le" (it is certainly hard of you) was the subjective evaluation on the part of the speaker. Here ye did not denote the same act but the same knowledge. This meant that "other people will believe that you work hard and I also think so". Hence, according to Xiao, this ye denoted "YE $E_{\mathrm{K}}$ ". For 11), through "ke wo ye shi ni fumu de erxifu" (but I am also your parents' daughter-in-law), the wife did not really mean that "*other people are your parents' daughters-in-law and also I am”. Instead, she demanded her rights as a daughter-in-law from her husband because he disallowed her to draw their parents into the young couple's private affairs. Therefore, according to Xiao, ye implied two similar acts of demanding, thus denoting some " $Y E_{U}$ ".

Xiao's study of ye, based on the three conceptual domains, as we think of it, did not operate purely at the lexical level, because ye is to be parsed within and not without sentences. From our viewpoint, the reason why ye in 9) expresses A does not lie in the existing similar affair but the highlighted A of the sentence, which contains the lexical term or pragmatic operator ye. According to the context of 9), the speaker stresses the act of his telling his wife all about his family background and therefore this sentence highlights $\mathrm{A}$, which makes it possible for ye to be oriented towards A. As regards 10), "ye zhen gou xinku de le" (it is certainly hard of you) is oriented towards the content of speech. However, according to the context, this is the speaker's evaluation of the aforementioned situation with a strong subjective bias, hence highlighting the speaker's K. So ye in this sentence is to be interpreted as " $Y E_{\mathrm{K}}$ ". In addition, we think that ye in 11) is A, but not $\mathrm{U}$. The wife told her husband that she would obey her parents, but her husband did not approve of this and required her not to nose into their parents' matters. All of these constitute the context of the wife's words "ke wo ye shi ni fumu de erxifu" (but I am also your parents' daughter-in-law). Due to her husband's disallowance, the wife's response should be relevant to her husband's act of disallowance demanding, according to Relevance Theory (see Sperber \& Wilson, 1986/1995/ 2001). Thus in this context, speech act is prominent/ostensive. The wife refused her husband's requirement by this utterance, so the sentence had better be taken as A (the pragmatic operator ye being endowed with the semantic load of A).

Is it possible, we wonder, to do researches of the three conceptual domains at a purely lexical level? We hold a negative attitude thereabout for its impracticality. Although any sentence is, in principle at least, a unity of $\mathrm{K}$, $\mathrm{A}$, and $\mathrm{U}$, it expresses different implications when highlighting one of these: $\mathrm{K}, \mathrm{A}$, or $\mathrm{U}$, and not two or all of them. In other words, $\mathrm{K}, \mathrm{A}$, and $\mathrm{U}$ respectively correspond to different implications. In that case, can we distinguish a single word's meanings of the three conceptual domains simply by means of its fixed senses and varied 
contextual implications of these three domains? Or can we figure out which sense/meaning of the/a word is A, which, K, and which, U?

Let's revisit the pragmatic operator ye in Xiao (2011) again. According to Modern Chinese Dictionary (6th ed.; 2012), ye possesses six meanings and uses:

(1) indicating the same case;

(2) used individually or repeatedly, stressing the coordinative relation of two things;

(3) used repeatedly, expressing the case in one way or another;

(4) used in transitional or concessive sentences (often co-occurring with suiran (虽然; although), jishi (即使; even if) of previous text), implying the same result;

(5) showing the meaning of euphemism;

(6) expressing emphasis (sometimes co-occurring with lian (连; even) of previous text).

So, let's see if it is possible to generalize the three conceptual domains of ye by simply considering its six meanings and uses but not taking syntactic or pragmatic factors into account. We find that, other things being equal, it will not work, for as far as the above expression of ye is concerned, its six meanings and corresponding usages are too vague. For instance, ye can be used to indicate the same case (as a presupposed previous case, explicated or implicated). Our question is: “In what case does ye have such a meaning or use?”. In the case of the same speech content? The same subjective inference? The same act? Thus, we cannot figure out which one of them (K, A, or $\mathrm{U})$ is prominent/ostensive simply via the fixed senses of ye (like sense (1) "indicating the same case”). That is to say, we cannot distinguish between the three by this token. It is the same case with the other five meanings and uses of the pragmatic operator ye. We must understand ye within a sentence or (beyond) sentences, investigating the macro-meaning of a sentence, as well as the tone and mood of the speaker. By doing this, we maintain, we can hope to pin down the exact sense/meaning of ye (like (1) 'indicating the same case' or others) as occurs in a particular situation, and likewise we can figure out which one of these, K, A, or U, is held prominent/ostensive.

We cannot do justice to the three conceptual domains of ye, nor with any other (such) words or pragmatic operators like yaobu (要不; otherwise) as addressed by Shi (2005), le $e_{2}$ ( ${ }_{2}$; a Chinese sentence-final particle) discusses by Xiao \& Shen (2009), laizhe (来着; also a Chinese sentence-final particle) discussed by Xie (2014), and so on and so forth-not simply through their fixed meanings and uses without considering any syntactic or/and pragmatic considerations. Hence it is our view that the study of the three conceptual domains at a purely lexical level is a theoretical impossibility, at least too huge a challenge.

So, what is the impact of syntactic and pragmatic factors on the study of the three conceptual domains as revealed only at a lexical level?

Firstly, we hold that the research of the three semantic domains as explored at the lexical level really should be a syntactic enterprise; namely it had better be treated with at the (higher) syntactic level. A single lexical item means nothing but as much sense or as many senses as a dictionary thinks of it and once used in a sentence, say, within the co-text and context, it is meant to mean something lively and dynamic. The gestalt or entirety of the utterance/sentence meaning to a great degree determines or gears the meaning of the word in question, or the three conceptual meanings of the word. From what we discussed above we can see that while analyzing the three conceptual meanings of ye, Xiao (2011) listed examples respectively corresponding to the three conceptual domains. So did other scholars studying the meanings of this or that word based likewise on the three conceptual domains. This showed that whilst these previous Chinese learners gave more or less consideration to syntactic factors/influence when studying lexically the three conceptual domains, they chose to confine themselves within the lexical/lexicon terrain, as though words were able to operate in isolation, contributing naturally to one of the three semantic domains.

Secondly, these lexical studies cannot serve the tentative explanation of the overlapping issue of the three domains. What we emphasized above is the fact that any sentence turns out to be a unity of K, A, and U, and not a realization of only one of them. In that case, is the trichotomy still necessary? And how can we distinguish between the three? If, as illustrated above, the lexical model is invalid in explaining the trichotomy, can the syntactic model work alone? No. One cannot hope to retrieve a satisfactory interpretation until and unless he tackles the issue pragma-syntactically, or, syntactically and pragmatically. For instance, the above examples of ye are merely sentences showing the unity of KAU, and according to our previous analysis, 9) highlights A, 10), K, and 11), A. This analysis is actually out of the question without the context of these sentences. The key to identification of the conceptual domain(s) of a sentence, rather than a word, other things be equal, is to find out the 
most prominent/ostensive one/domain, the domain that prevails, in a specific context. It is not generally a question of yes or no, nor a question of which, but a question of degree, a question of perspective/perspectivization. To what extent, or from what perspective, if we may ask of a sentence, is it $\mathrm{A}, \mathrm{K}$ or $\mathrm{U}$ at all?

Some previous researchers have touched upon domain overlap (ping) in their studies, such as Xiao \& Shen (2009), Xiao (2011) and so forth. Although they occasionally mentioned the influence of context (enjoying a mild proportion of pragmatic involvement), they failed to promote their studies to what we think should be the pragma-syntactic stratum.

In consideration of the disadvantages in previous (lexical) studies of the three conceptual domains, we propose the "Lexico-Pragma-Syntactic Hypothesis" on three conceptual domains, whose central idea is that the study of three conceptual domains should be such as encompasses the three linguistic levels, with pragmatics playing a prevailing role.

\section{The "Lexico-Pragma-Syntactic Hypothesis" on Three Conceptual Domains}

\subsection{Syntactico-Determinism}

As pointed out above, the lexical study of the three conceptual domains can and should be brought about in the framework of syntactic or pragma-syntactic studies due to the fact that the former is impossible without the latter. From our point of view, it is the macroscopic pragma-syntactic effect that can account for a linguistic unit being, belonging or attributing to one of the three semantic domains as studied before.

For one thing, the lexical meaning discussion or lexical domain attribution cannot achieve much without anchoring a word in a sentence, among other things. The relationship between semantics and syntax has long been a controversy but the idea that the two areas or approaches of language studies are complementary to each other has been broadly accepted. As far as lexical meaning is concerned, it is to be pinned down by more than the word in question. The sense inventory as we detect in a dictionary make a potential list of them, to be narrowed down by sentential cues in a text. Take the Chinese character qin (亲; honey/baby). "In ancient Chinese, qin is used as a monosyllabic (more frequently) or polysyllabic unit. The meanings of the word as a monosyllabic unit can be figured out by the sentence where it lies. This means that the structure of the sentence determines the functions (or meanings) of the unit” (Feng, 2014). It is true that it remains open to question whether and how the structure of the sentence could exactly determine the meanings of a word, but as the word qin as a monosyllabic unit demonstrates, its meaning is so uncertain and unclear until we find it in a specific sentence, hence textualization plus contextualization. Please look at a few examples.

12) 可以 全 生, 可以 养 亲。

keyi quan sheng keyi yang qin

could all alive could breed parents

One could keep alive and become filial to his parents.

(U; parents; Yang Sheng Zhu of Zhuangzi; qtd. from Feng, 2014)

13) 爱臣太亲, 必危其身。

ai chen tai qin bi wei qi shen

love official very intimate surely damage your body

Your majesty's going too close to your officials is a huge risk.

(A; intimate; Ai Chen of Hanfeizi; qtd., ibid.)

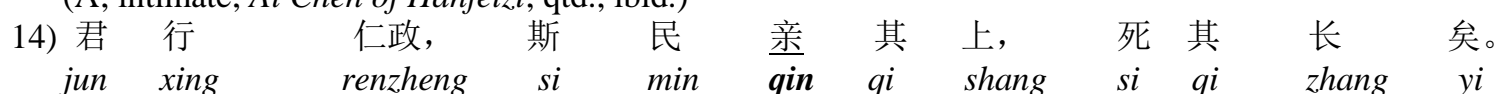

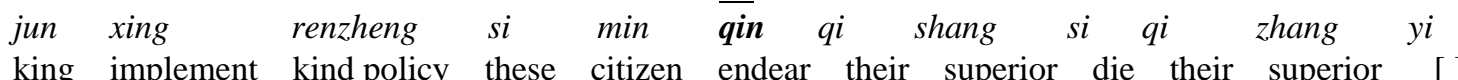

If your majesty carries out the policy of benevolence, the masses will stay so close to your government at the risk of their lives.

(A; endear; Liang Hui Wang Xia of Mengzi; qtd., ibid.)

$\begin{array}{ccc}\text { 15) } & \text { 亲 } & \text { 命 } \\ \text { wang } & \text { qin } & \text { ming zhi }\end{array}$

king personally order this

The king personally gave the word.

(U; personally; Da Ya-Han Yi of Shi Jing; qtd., ibid.)

The meanings and uses of qin vary from case to case, as seen in the above examples. It is these sentences that 
help us to make sure about what the word is meant to mean. The single character qin cannot successfully express any meanings unless sententialized-co-textualized and contextualized. With sentences before and after a qin one, as uttered by a particular locutor to a hearer in a particular place at a particular time, the lexical item qin (actually any conceivable word in this case) has its meaning safely anchored.

Moreover, the functions of a word are governed within and by the entirety of a sentence. In addition to the referential, denotative and connotative function, a word may have such by-functions as euphemism, emphasis or down-toning. In our view, even if the sentential function is not in every aspect identical to the lexical function (function of each lexical item that co-occurs in the sentence), they are more or less iconic to one another. Again the ye example. Most of the six meanings of the word (see part 2) have to do with such by-functions, which all find expression only in a sentence or sentences. For instance, without a sentence prior to the sentence where ye occurs, meaning (1) "indicating the same case” does not hold. Meaning (2) "used individually or repeatedly, stressing the coordinative relation of two things" is possible only with more than two things for comparison, in the same or different sentences. So is the case with meaning (3) "used repeatedly, expressing the case in one way or another”. Meaning (4) "used in transitional or concessive sentences” naturally is inter-sententially bound. Meaning (5) "showing the meaning of euphemism” and meaning (6) “expressing emphasis”, however, are typical by-functions of the word. See more examples:

$\begin{array}{ccclllllll}\text { 16) 尽管 } & \text { 身体 } & \text { 不 } & \text { 舒服, } & \text { 他 } & \text { 也 } & \text { 还是 } & \text { 坚持 } & \text { 完成 } & \text { 了 任务。 } \\ \text { jinguan } & \text { shenti } & \text { bu } & \text { shufu } & \text { ta } & \text { ye } & \text { haishi jianchi } & \text { wancheng le } & \text { renwu } \\ \text { Although } & \text { body not comfortable } & \text { he } & \text { also still } & \text { persist } & \text { finish } & \text { [ ] task }\end{array}$ Although feeling under the weather, he [ ] pushed himself through the task.

(A; expressing transition)

17) 毕竟是个孩子, 你也不能太苛刻了啊!

bijing shi ge haizi ni ye buneng tai keke le a

after all is a child you also cannot very rigor [ ] [ ]

There is simply no need to ask too much. He's a child after all.

(A; expressing euphemism)

18) 连这么 小 的孩子也会说英语了, 你 得 加油啦!

lian zheme xiao de haizi ye hui shuo yingyu le ni dei jiayou la

even so little [] child also can say English [ ] you have to increase oil []

Even such a young child could speak English. You have to work harder.

(A; expressing emphasis)

In the above three examples, ye respectively marks transition, euphemism and emphasis. Its three functions are closely relevant to the meanings and tones of the three sentences where it occurs. In 16), jinguan (尽管; although) leads to a concessive clause. We know that it usually co-occurs with danshi (但是; but) in the Chinese language. However, in this case we cannot find the latter but ye. Therefore jinguan leading to the concessive clause forces ye to adopt the function of danshi with a transitional tone. For 17), this sentence means "you should not be too severe to a child”, expressing the undesirable implication of blaming. However, the question mark at the end of the sentence helps downtone the blade of criticism, hence making the entire sentence more or less euphemistic. As a result, ye in this sentence takes on the euphemizing function. With respect to 18), the speaker intends to stress (that) "a child can speak English" as an indicator of urging the hearer to put his shoulders to the wheel of his job. The Chinese character lian (连; even) often co-occurs with dou (都; all/both), expressing polar/polarity emphasis. As we cannot find the expected dou-the coordinating conjunction of ye, but ye alone, ye is really coerced to implement dou's emphasizing function.

From the above examples and analysis, we can see that the word ye either means nothing in isolation or means just an array of dictionary/lexicographical meanings so that one hardly knows which meaning the word expresses without any textual or contextual cues. All the six semantic contents of the word ye are hollow without a sentence, and only when the word is put in the soil of a text and context can it freely mean one of the six alternatives listed above. If words help construct a sentence, a sentence-actually its structure or construction-determines the sentential meaning and utterance meaning, let alone help narrow or pin down the exact meaning of a particular word that is used in a sentence. And we believe this more or less agrees with some relevant claims of construction grammar (see Goldberg, 1995, 2006). That is why we maintain that the lexical study of the three conceptual domains does not mean much to the study of (those few) words, not to speak of that of sentences or clauses. Or, investigation of KAU is uneasy with words, if possible at all, and we suggest a senten- 
tial/syntactic approach—study of the three semantic domains of sentences (perhaps also clauses), but not merely words or lexicon, by a sentential, supra-sentential (co-textual) and of course pragmatic approach/perspective.

\subsection{Pragma-Disambiguation}

Even though we highlight the macroscopic syntactic/sentential determinism in determining which of the three conceptual domains a sentence/clause really performs, we must not hesitate to acknowledge that there still remain problems unresolved. We are concerned, for instance, with the multiplicity/ambivalence of a linguistic unit, say, a sentence, in terms of semantic domains. In other words, if it is capable of expressing more than one meaning, which meaning should be responsible for which of the three semantic domains, or is there a one-to-one correspondence? Syntax alone cannot solve this problem. Now that there exists a common phenomenon of domain overlapping, it is partly or wholly due to the semantic overlapping or polysemy. So the distinction of $\mathrm{K}, \mathrm{A}$, and $U$ from one another, as far as a sentence is concerned, is an uneasy if not impossible job unless interfered by pragmatics.

To begin with, "polysemy is a prevailing phenomenon in any language” (Hou, 2008: p. 387). Then, language itself is vague and ambiguous (ibid.). Besides, even for a seemingly semantically simple and clear sentence, it carries varied meaning, from implicitness to explicitness, from literality to non-literality, from explicature to implicature (ibid.). So if we want to figure out the exact meaning of a sentence, the context of the sentence and the pragmatic goal of the speaker necessarily are to be brought into account.

"Context means the environment of the verbal activities. There is no language activity in vacuum. Thus, people's language activity and speech acts can only be understood properly within the real context" (ibid.: p. 315). That is to say, any sentence can only be understood exactly when put into a specific context as shown by the following example.

19) (Husband asks wife to go to their daughter's room and see if she has taken medicine on time)

H: Did she take it?

W: No.

( $\mathrm{H}=$ husband; $\mathrm{W}=$ wife)

Without the contextual information in the bracket, we cannot understand what they are talking about. Who is she? What should she take? It is the specific context that helps us find out the exact meaning of the conversation between the couple.

According to Chen \& Wen (1997), restrictive and interpretative functions are the most basic functions of context. "Restrictive function is such that context limits the production and interpretation of language" and "interpretative function is most evident in explaining situational meanings and eliminating ambiguity and vagueness" (also see Hou, 2008: p. 403). As seen from 19), the context restricts the conversational content of the couple relevant to their daughter's taking medicine and we rely on such a restriction to gear the sentential comprehension. Also, the context interprets the meanings of the couple's words in this situation and thus eliminates other possible meanings or meaning retrieval(s) (for example, otherwise the husband may justifiably ask her wife if their niece, mother, daughter-in-law whatsoever has taken (eaten, purchased, polished, filed up, etc.) an umbrella, raincoat, a piece (of chess, as in a chess game), car, computer whatsoever, if and only if it is relevant.

As discussed above, 7) highlights different conceptual meanings when rooted in different contexts, and we strongly hold that context does help us distinguish between $\mathrm{K}$, A and $\mathrm{U}$, if it matters to determination of semantic domains. "We turn to context for help in all cases of semantic vagueness or ambiguity, just for its orientation capacity. It works with every aspect of language communication like phonological, lexical, grammatical, semantic, pragmatic, rhetorical, logical and textual levels” (ibid.). As seen above, a sentence can be A, K, or U. The speaker's communicative/pragmatic goal contributes/leads to the prominence/ostension of this or that conceptual domain. This goal is seen also in a particular context. Therefore, context is as significant to disambiguation in terms of sentential or lexical meaning as to that in terms of sentential (or even lexical/constructional) function, be it (part) A, K or U.

Thanks to human/communicative intentionality, people utter words to do a thing, or pragmatically to perform a (Searlean) speech act, or a (Meyan) pragmatic act (pract). The problem here is that a locutor by means of a sentence can sound/be vague or ambivalent in terms of function, hence multifunctionality. If-conditionals, for instance, can mean an array of different acts, in a default context. So the particularity of contextual factors interferes in the functional narrow-down. Only in the context of 19) above perhaps can the husband convey the act/pract of asking (A), or (inter)rogative (A), or as we at times interpret it, the act/pract of indirect directive (A), 
be it polite request or impolite command.

The act of asking (A), or (inter)rogative (A), as a speech or pragmatic act, like the act/pract of indirect directive (A), naturally makes the issue all the more complicated, to be addressed later on (see 3.3).

Now let us move back to 7). In the context of $8 a$ ), $S_{1}$ asks inquires about the content of $S_{2}$ 's speech, so $S_{2}$ 's pragmatic goal as a speaker is to clearly tell $S_{1}$ something new/unknown-locution (ary) content. Thus $S_{2}$ 's response is an objective statement, the content of speech, highlighting $U$. As for 8b), $S_{1}$ asks how well $S_{2}$ knows that person. Here $S_{2}$ 's pragmatic goal is not stating something new but showing $S_{1}$ merely what he knows, to show his knowledge of him. $\mathrm{S}_{2}$ 's words serve knowledge or $\mathrm{K}$. In 8c), $\mathrm{S}_{1}$ is supposed to make sure about a presumption (he is more than likely to be a good swimmer) by means of a tag question (pay attention to "can't he?”), so $\mathrm{S}_{2}$ 's response serves as (emphatic) confirmation/assurance (contrary to negation or denial), hence A.

\section{3. "Lexico-Pragma-Syntactic Hypothesis" on Three Conceptual Domains}

In consideration of disadvantages with previous researchers like Sweetser and Shen, we put forward the "Lexico-Pragma-Syntactic Hypothesis” on the three conceptual domains.

The relationship between lexical, syntactic and pragmatic levels is multidimentional and the three domains of KAU cannot simply hold or be accounted for at any one of the three levels. The study of three conceptual domains is consequently such as encompasses them all.

When we say a word denotes $\mathrm{A} / \mathrm{K} / \mathrm{U}$, this means that the word triggers or helps highlight the domain of $\mathrm{A} / \mathrm{K} / \mathrm{U}$ in a certain sentence. This by no means suggests that the word itself expresses anything like $\mathrm{A} / \mathrm{K} / \mathrm{U}$.

Let us go over 9), 10), and 11) for further illustration. The pragmatic operator ye in 9) triggers or helps highlight the speaker's A. In 10), it is the speaker's K, and in 11), the speaker's A. However, it is unwise to infer or conclude that the word in one of these examples denotes $\mathrm{A} / \mathrm{K} / \mathrm{U}$ without/outside the sentence in question, or more than one sentence for the build-up of a co-text and really a context alongside. If a sentence expresses $\mathrm{A} / \mathrm{K} / \mathrm{U}$, as we interpret it, it does no more than highlighting $\mathrm{A} / \mathrm{K} / \mathrm{U}$ in a certain context. Does 7) convey the meaning of $\mathrm{A}$ ? In the context of $8 \mathrm{a}$ ), $\mathrm{U}$ is prominent/ostensive, in the context of $8 \mathrm{~b}$ ), it is $\mathrm{K}$, and in the context of 8c), it is $\mathrm{A}$, that is prominent/ostensive.

Now we come to the complication of the Searlean act system whose matrix permits in all utterances to be a type of speech act, and no other (theoretically). An utterance is a representative so that it differs from and does not fall within the category of one of the other popular speech acts, like directive. Likewise, an utterance is a directive to such an extent that it meets no requirement/prerequisites for any other type of speech act, like commissive. As mentioned above, utterances are vague, other things being equal, in meaning and in function. If the semantic vagueness is taken for granted or accepted as something natural, we should say that functional/illocutional ambivalence is also a common thing (see Hou, 2005).

So, with all examples in this paper and more to come, no one is absolutely certain about the speech act or pract of an utterance unless he is given sufficient relevant contextual cues. Speaking of a word or a sentence, anyone claiming undoubtedly about the illocutional attributes is actually doing something problematic and theoretically risky.

When we say (in 3.2) of 8a-c) that the act/pract is asking (A) or (inter)rogtive (A), or confirmation/representative (A), we risk over-simplification, because we are comparatively short of contextual cues (given the bracketed information). Given the above supposition that an utterance enjoys more or less of illocutional ambivalence, the attribution of 8a-c) in terms of $\mathrm{U}, \mathrm{K}$ or $\mathrm{A}$ is a matter of degree.

In the context of 8a), $S_{2}$ 's response is more of $U$ than of $A$ or $K$. With $\left.8 b\right), S_{2}$ is more of $K$ than of $U$ or $A$. In 8c), $S_{2}$ 's utterance is more of A (confirmation/assurance) than of $U$ or K. In fact, with 8a-c), $S_{2}$ 's utterance carries a greater proportion of this or that domain.

There arises the issue of perspectivization, as mentioned above in passing. From whose perspective, or to whom, is an utterance $\mathrm{K}, \mathrm{U}$ or $\mathrm{A}$ ? Or, from whose perspective, or to whom, is an utterance more of $\mathrm{K}$, say, than of $\mathrm{U}$ or $\mathrm{A}$ ?

With 8a-c) again, $S_{1}$ and $S_{2}$ are two roles in the dialogue, and we should of course put $S_{1}$ and $S_{2}$ in the context of conversation. The above attribution may hold true on this score. But it may not hold from the perspective of the reporter, and audience. Let us suppose a scene of $S_{1}$ and $S_{2}$ conversing somewhere about a certain topic. As a friend of yours that overhears this chunk of talk, I come to see you, say, to see if someone can take my three-year-old son to a swimming tour, and you reportingly repeat the talk between $S_{1}$ and $S_{2}$ both whom you 
happen to know. Now I would say that in $8 a), S_{2}$ 's utterance denotes his knowledge, for it is the swimming-capacity knowledge that counts for my case. So is the case with 8b-c).

In short, we take into consideration the roles of $S_{1}$ and $S_{2}$ and more communicators in cases of illocutionary/ domain attribution, and the perspectives of more or other people, like communicators about communicators, reporters, overhearers, eavesdroppers, and so on.

The question had better be, what is an utterance, $A, K$, or $\mathrm{U}$, as locutor $\mathrm{S}_{1}$ or $\mathrm{S}_{2}$ interprets it, or as you or I or audience think of it?

\section{Conclusion}

There have been many studies about the three conceptual domains in China, "content domain”, "epistemic domain”, and "speech-act domain” (Sweetserian trichotomy), or the corresponding A(cting), K(knowing), U(ttering) (Shenian trichotomy) — our KAU. These studies, as outlined above, showed clearly how the framework of three conceptual domains well explained previously inexplicable and untraveled language phenomena. Nevertheless, while basing their studies on Sweetserian or Shenian framework, these researchers did not realize that Sweetser (1990/2002) and Shen (2003) had somehow theoretically confused the speaker, the listener and the other. Their content domain/A did not correspond to the speaker, but the epistemic domain/K and the speech-act domain/U did. So we think that the premise of studying the three conceptual domains is to make it clear to whom $\mathrm{K}$, $\mathrm{A}$, and $\mathrm{U}$ respectively belongs or pertains.

We briefly review previous studies about three conceptual domains and clarify the confusion issue of the three in the perspective of the speaker, the listener and the other. On this basis, we analyze disadvantages of the study of the three exclusively at the lexical level, believing that previous studies failed to highlight the importance of syntactic and pragmatic factors to lexical level and thus did not rise to pragma-syntactic level though mentioned randomly in passing. On account of this, we propose the "Lexico-Pragma-Syntactic Hypothesis" on the three conceptual domains, maintaining that the three domains should be studied by taking the multi-dimensional relationship among three linguistic levels into consideration, with pragmatics playing a prevailing leading role.

What we want to emphasize is that this is not a criticism to Sweetser (1990/2002), and Shen (2003), but just a trivial complement based on their theory. Also, previous scholars did not wholly ignore syntactic and pragmatic factors in their studies about the three conceptual domains at the lexical level. Instead, they just paid more attention to these two while unfortunately failing to promote their studies to the pragma-syntactic level. For this reason, we do not mean to criticize them, but base our study on them. Also, what we discussed above is far from the development of theirs but only our own points of view. Thus our opinions are certainly worth rethinking, and open to criticism.

\section{Acknowledgements}

Thanks for the financial support of Social Science Fund/Programme of the State: Pragma-Translatology: Studies of Metaphorical Talk Translation (12BYY017), Social Science Fund/Programme of the Ministry of Education: Lexico-Constructional Pragmatics: The First Bridge of Pragma-Translatology (12XJA740008) and Scientific Research Fund/Programme of Huaqiao University: Pragma-Translatology (15SKBS102), and General Linguistics (14YJG08). We also thank Jingjing Chen, Chenying Mei, Yalian Li and Tingting Wan for advice.

\section{References}

Austin, J. L. (1962/2002). How to Do Things with Words. Oxford: OUP. Beijing: Beijing Foreign Language Teaching and Research Press.

Chen, Z. A., \& Wen, X. (1997). A Tentative Study of Features and Functions of Context. Journal of Foreign Languages, 4 , 22-26.

Deng, S. Y. (2012). A Syntactic Analysis of the Speech Act Domain: Evidence from sin (先) in Cantonese. Linguistic Science, 1, 9-14.

Fan, Z. Q. (2014). The Mechanism of Three-Domain Theory: Metaphorical or Metonymic? Journal of Zhejiang International Studies University, 1, 20-26.

Feng, M. (2014). A Lexico-Pragmatic Study of Addressing Term qin (亲). Shandong Foreign Language Teaching Journal, 1, 
78-81.

Goldberg, A. E. (1995). A Construction Grammar Approach to Argument Structure. Chicago \& London: University of Chicago Press.

Goldberg, A. E. (2006). Constructions at Work: The Nature of Generalization in Language. Oxford: OUP.

Hou, G. J. (2005). Pragma-Linguistic Strategies for Transform-Transfer Modulation. Modern Rhetoric, 5, 40-44.

Hou, G. J. (2008). Dominant Pragmatic Issues and the Way to Pragmatranslatology. Chengdu: Sichuan University Press.

Langacker, R. (1987). Foundations of Cognitive Grammar (Vol. I): Theoretical Prerequisites. Stanford: Stanford University Press.

Langacker, R. (1991). Foundations of Cognitive Grammar (Vol. II): Descriptive Application. Stanford: Stanford University Press.

Li, J. X., \& Liu, Y. (2004). Differences between youyu (由于) and jiran (既然) in Subjectivity. Chinese Language, 2, 123128.

Searle, J. (1969/2001). Speech Acts: An Essay in the Philosophy of Language. Cambridge: CUP. Beijing: Beijing Foreign Language Teaching and Research Press.

Shen, J. X. (2003). Compound Sentences in Three Conceptual Domains: Acting, Knowing, and Uttering. Chinese Language, 3, 195-204.

Shi, J. S. (2005). Grammaticalization of yaobu (要不): Pragmatic Mechanism and Formal Changes. Journal of PLA University of Foreign Languages, 6, 6-13.

Sperber, D., \& Wilson, D. (1986/1995/2001). Relevance: Communication and Cognition. Oxford: Blackwell. Beijing: Beijing Foreign Language Teaching and Research Press.

Sweetser, E. (1990/2002). From Etymology to Pragmatics Metaphorical and Cultural Aspects of Semantic Structure. Cambridge: CUP. Beijing: Peking University Press.

Wang, L. C. (2012). The Study on Content, Epistemic and Speech Act Domain of Hypothesis Complex Sentences. Master Thesis, Harbin: Harbin Normal University.

Wang, L. X. (2011). Three Conceptual Domains of Inclusive Adverbs dou (都) and yigai (一概) and Relevant Issues. Journal of Ningxia University (Humanities \& Social Sciences), 2, 15-19.

Xiao, Z. Y. (2011). Three Conceptual Domains of Adverb ye (也). Zhejiang Academic Journal, 4, 100-104.

Xiao, Z. Y., \& Shen, J. X. (2009). Three Domains of the Sentence-Final Particle $l e_{2}\left({ }_{2}\right)$ in Mandarin Chinese. Chinese Language, 6, 518-527.

Xie, C. M. (2014). On the Three Usages of the Sentence-Final Particle laizhe (来着): A Perspective of Three Conceptual Domains and Subjectivity Theory. Language Teaching and Linguistic Studies, 1, 67-74.

Xu, L. J. (2008). Establishment of Subjectification Model of English If-Conditionals. Journal of Foreign Languages, 1, 6267.

Zhang, B. S. (2011). My Opinions of Three Domains of the Sentence-Final Particle $l e_{2}\left({ }^{2}\right)$ in Mandarin Chinese. Chinese Language, 5, 427-429. 